\title{
PROPOSTA DE UM FRAMEWORK PARA SELEÇÃO DE UM CHASSI DE ÔNIBUS URBANO: UMA ABORDAGEM A PARTIR DO QUADRO DE TOMADA DE DECISÕES E DOS MÉTODOS AHP E AHP-GAUSSIANO
}

\author{
Brayan de Almeida Lima (UNIGRANRIO) brayan_lima@hotmail.com.br \\ Marcos dos Santos (IME) marcosdossantos@ime.eb.br \\ Daniel Augusto de Moura Pereira (UFCG) danielmoura@ufcg.edu.br \\ Andrei Eduardo de Souza Gomes (ESPM) contato@ andreigomes.com.br
}

\section{Resumo}

Um dos problemas enfrentados pelas empresas de transporte é a renovação de sua frota, cujo objetivo é atender as leis, com menos emissões de gases poluentes ou redução da idade média da frota, estar a par das novas tecnologias, estar à frente de seus concorrentes, entre outros fatores, sendo este processo uma etapa que demandará tempo e consequentemente dinheiro para as empresas. O propósito deste trabalho é apresentar um framework para ser mais assertivo no processo de seleção de novos veículos, tendo como objeto de estudo dois chassis de ônibus urbano das marcas Mercedes-Benz e Volkswagen Caminhões e Ônibus, MB OF1721 e o MAN 17.230, respectivamente, tendo como método de Apoio a Tomada de Decisão Multicritério o AHP-Gaussiano. Antes de realizar a seleção, foi feito o levantamento das informações necessárias para o processo, como a recompensa, o cenário e a estratégia empregada, assim como as alternativas e os atributos utilizados no processo decisório, a partir do Quadro de Tomada de Decisões. Após aplicação do método a melhor alternativa foi o chassi MB OF-1721, líder de vendas no Brasil. Esta seleção poderá beneficiar os gestores responsáveis e consequentemente a população que utiliza este meio de transporte público.

Palavras-Chaves: Tomada de decisão, AHP-Gaussiano, Quadro de decisões, Chassi de ônibus, Renovação de frota.

\section{Introdução}

As empresas de pequeno, médio ou grande porte, independente do setor em que atuam, podem dispor de uma frota de veículos para diferentes fins de transporte, como o de carga ou de pessoas. Possuir frota própria ou terceirizada, são formas de se manter estes veículos a disposição da empresa, mas independentemente de como se mantém estes veículos é importante saber realizar a gestão dos mesmos da melhor maneira, em observância aos pontos 
que podem ser apresentados as melhorias, para gerar economia e eficiência para a organização.

Segundo o Serviço Brasileiro de Apoio às Micro e Pequenas Empresas - SEBRAE (2016) as condições da malha rodoviária no Brasil ocasionam a necessidade antecipada da realização de manutenções da frota, o que acarreta o aumento dos custos. Outro ponto a ser analisado é o custo com o combustível, que sofre reajustes cada vez mais ao longo dos anos.

Para empresas do setor rodoviário de transportes, carga ou passageiros, é fundamental a realização de um estudo sobre o veículo que será incorporado a frota, já que este poderá permanecer como um ativo durante mais de 10 anos. A assertividade na tomada de decisão é fundamental para a seleção de algo que se queira adquirir.

Quando se fala na aquisição de um veículo é importante considerar as mudanças tecnológicas, as que ocorrem nas leis, principalmente, seja em esfera, municipal, estadual ou federal, ao meio ambiente, a facilidade com aquisição de peças de reposição, entre outros critérios de suma importância para a manutenção da frota.

As mudanças no setor econômico e a influente mudança nas normas sanitárias também são importantes e precisam ser levadas em consideração no processo de tomada de decisão. Fatores externos como a pandemia do COVID-19 tem afetado a venda de ônibus, como diz a Fenabrave (2020), onde afirma que a demanda reduziu de forma drástica, ocasionando retração das vendas em 33\%. É importante neste momento as empresas possuírem um plano estruturado para realização da modernização de sua frota já pensando em possíveis casos futuros e aprendizado com o presente.

O boletim de tendências do SEBRAE (2016) aponta alguns dados pertinentes ao uso dos transportes rodoviários, onde diz que as empresas são os maiores compradores de veículos novos, devido à necessidade e, também, entendimento de que manter um veículo novo pode ser mais econômico. Os transportes de cargas e passageiros são, respectivamente, o $3^{\circ}$ e $4^{\circ}$ lugar dentre as atividades econômicas, o quilômetro rodado por estes veículos anualmente são muito maior quando comparado a um veículo não comercial.

A frota de ônibus no Brasil aumentou em 2,1\% no ano de 2020, aumentando a idade média de 17 para 17,5 anos. A região brasileira que mais concentra ônibus é o Sudeste com $46 \%$ do total nacional. $\mathrm{O}$ volume de ônibus que foram negociados por idade não apresentou mudanças significativas. (FENABRAVE, 2020) 
Um dos problemas enfrentados pelas empresas de transporte é a renovação de sua frota, onde mesmo sendo uma etapa planejada, ainda assim demandará tempo e consequentemente consumirá os recursos financeiros e humanos, pois os custos de aquisição desses novos veículos somados podem estar compreendidos na casa dos milhões, além da disponibilidade de um comitê para realizar todo o projeto e, também, o processo decisório. O processo de tomada de decisão tem por finalidade fornecer a melhor opção possível dentre determinadas alternativas e seus respectivos atributos, pois é um alto investimento substituir toda uma frota de veículos.

Se considerarmos, por exemplo, que um veículo de transporte de pessoas, um ônibus urbano, que realiza um trajeto municipal ou intermunicipal, custa em média R $\$ 350$ mil, apenas o chassi, e que uma empresa possui 10 ônibus constituindo sua frota e deseja substitui-los, será um investimento de R \$ 3,5 milhões, e se considerarmos a compra das carrocerias, avaliada no mesmo valor dos chassis, aproximadamente, ao todo será um custo de R 77 milhões. Uma empresa de transporte de médio ou grande porte, possui em torno de 100 ônibus compondo sua frota. Considerando o setor rodoviário interestadual de transporte de passageiros, uma unidade de ônibus rodoviário completo (chassi + carroceria), o custo de aquisição está em média R \$ 1,5 milhão.

Os requisitos para a decisão podem estar dispostos de acordo com as necessidades ou com o grau de importância para cada empresa, ou decisor, na aquisição de um veículo. Muitas empresas optam por marcas consolidadas no mercado e já utilizadas por elas. O fato de muitas delas já possuírem programas estruturados na gestão de seus veículos, como o plano de manutenção, o treinamento, tanto na operação quanto na manutenção, e o relacionamento com os fornecedores, faz com que elas optem pelo modelo já adquirido anteriormente. Muitas destas decisões são baseadas no instinto ou no subconsciente, ou ainda, baseadas na instituição.

De que maneira é possível ser mais assertivo no processo de seleção de um modelo de chassi de ônibus urbano, em rotas municipais e intermunicipais, no transporte de passageiros?

Dado questionamento acima, neste contexto, o referente trabalho está disposto a apresentar um framework para auxílio na seleção de um chassi ônibus urbano, para transporte de passageiros, com a utilização do modelo visual para auxílio em tomadas de decisões estratégicas (Quadro de Tomada de Decisão) e do método de Apoio a Tomada de Decisão Multicritério AHP-Gaussiano. 


\section{Fundamentação teórica}

\subsection{Tomada de decisão}

A Tomada de Decisão pode ocorrer através de um único indivíduo, o decisor, ou um conjunto de indivíduos, os decisores, com o objetivo de alcançar o melhor resultado para um determinado problema. (GOMES; GOMES, 2019, p.1)

A Tomada de Decisão deve ser aplicada sempre que houver a necessidade de solução a um problema, mesmo que haja a ligação deste problema a uma única solução, realizar ou não realizar tal ação. Direcionar o foco a um determinado problema viabiliza a possibilidade de direcionar todos os esforços corretamente ao processo. (GOMES; GOMES, 2019, p.1)

Alves et al. (2020) diz que a Pesquisa Operacional (PO) é uma ciência que possui como principal função, fornecer ferramentas de auxílio ao processo decisório, que por influência de vários fatores, acabam por se tornar complexas a ponto de necessitar mais do que uma simples folha de papel para serem resolvidas. Os autores abordam a PO para descobrir o mix ótimo de produtos que deverá ser encomendado para um evento universitário, de forma a maximizar o lucro considerando as restrições do problema.

A PO pode ser utilizada para auxiliar os gestores no processo decisório, de forma racional, pois sua função é modelar a realidade e permitir a construção de cenários. Os autores utilizaram a PO em um estudo sobre a realização de um plano de compra otimizado de itens para a manutenção preventiva de caminhões, observando diversos critérios pertinentes ao processo decisório. (TADAIESKY et al., 2020)

Franco et al. (2020) utilizaram o processo de Tomada de Decisão Multicritério para realizar a seleção de uma empresa terceirizada para o trabalho de manutenção e aferição em equipamentos hospitalares, de forma que atendesse aos múltiplos requisitos impostos na seleção, alcançando o resultado satisfatório.

\subsubsection{AHP-Gaussiano}

O método multicritério Analytic Hierarchy Process - Gaussian (AHP-Gaussiano), foi introduzido por Santos, Costa e Gomes (2021), onde visa uma nova abordagem ao método original AHP, que se baseia em uma análise de sensibilidade proveniente do fator Gaussiano. 
Com essa abordagem é possível obter os pesos dos atributos a partir de inputs quantitativos das alternativas em seus respectivos atributos, a partir dos dados inseridos na matriz de decisão. (SANTOS; COSTA; GOMES, 2021)

O método visa acabar com a dependência que existe da matriz de avaliação entre os critérios, eliminando a necessidade de avaliação par a par entre os atributos na obtenção dos seus respectivos pesos, onde os cálculos incluem a média e o desvio padrão para a alcance da ordenação das alternativas. O AHP-Gaussiano pertence aos métodos compensatórios, os atributos são independentes e os atributos qualitativos são convertidos em atributos quantitativos. (SANTOS; COSTA; GOMES, 2021)

Etapas do método AHP-Gaussiano:

- A primeira etapa do método é estabelecer a matriz de decisão, com as alternativas e critérios a serem julgados no processo decisório;

- Após estabelecer a matriz de decisão, é realizada a normalização dos atributos, para valores que se queira maximizar, monotônico de lucro, utiliza-se a fórmula (1).

$$
N=\frac{a_{i j}}{\sum a_{i j}}(1)
$$

Para valores que se queira minimizar, monotônico de custo, utiliza-se a fórmula (2).

$$
N=\frac{\left(\frac{1}{a_{i j}}\right)}{\left(\frac{a_{i j}}{\sum a_{i j}}\right)}(2)
$$

— A segunda etapa é calcular a média das alternativas;

— A terceira etapa é calcular o desvio padrão de cada alternativa para cada critério;

- A quarta etapa é calcular o fator Gaussiano para cada critério;

— A quinta etapa é multiplicar o fator Gaussiano pela matriz de decisão 
— A sexta etapa consiste na normalização dos resultados; e

— Na sétima etapa é obtido a ordenação das alternativas.

\subsection{Quadro de tomada de decisão}

As empresas que estão investindo na modernização de suas frotas devem traçar um planejamento adequado para este projeto, estruturando a maneira de como irá realizar a tomada de decisão, inserindo todas as informações pertinentes ao processo, como o objetivo, o cenário, a estratégia, o que implica na decisão, os desafios, quem está envolvido no projeto e os recursos.

Para estruturar o problema apresentado neste trabalho, foi utilizado o modelo visual para auxílio em tomadas de decisões estratégicas desenvolvido por Andrei Gomes no programa de pós-graduação da ESPM Rio, no mestrado em Gestão da Economia Criativa.

Figura 1 - Quadro de Tomada de Decisões - Andrei Gomes

\begin{tabular}{|c|c|c|c|c|c|c|}
\hline \multicolumn{2}{|c|}{ Quadro de Tomada de Decisões } & \multicolumn{2}{|c|}{ Projetrado por: BRAYAN LMEA } & Projetrado para: EAPRESA ONIEUS RJXPTO & Data: 100552021 & \begin{tabular}{|l|} 
Fase: 1 \\
\end{tabular} \\
\hline 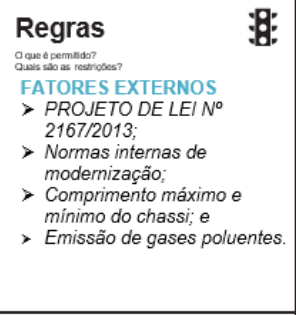 & 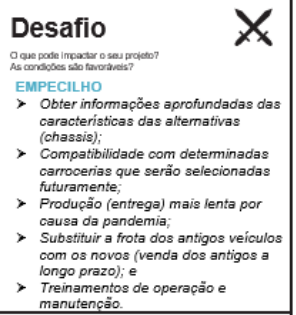 & \multirow{2}{*}{\multicolumn{2}{|c|}{ 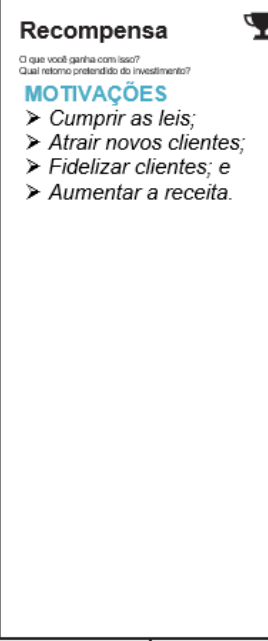 }} & 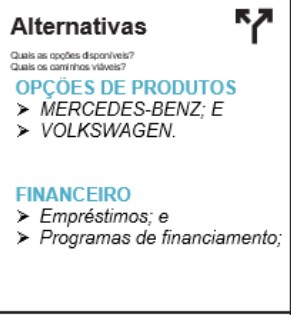 & $\begin{array}{l}\text { Decisão a faz } \\
\text { oquevodratioer } \\
>\text { Selecionar a of } \\
\text { melhor resultac } \\
\text { critérios pré-es } \\
\text { acordo com on } \\
\text { apoio a tomadé } \\
>\text { Pré-seleção da } \\
\text { partir de um bu } \\
>\text { Visitas recorrer } \\
\text { eventos de ônit } \\
>\text { Visitas aos forn } \\
>\text { Networking. }\end{array}$ & $\begin{array}{l}\quad \checkmark \\
\quad \text { äo com o } \\
\text { dentre os } \\
\text { belecidos de } \\
\text { todo de } \\
\text { edecisão; } \\
\text { alternativas a } \\
\text { et; } \\
\text { s a feiras e } \\
\text { s (técnicas); } \\
\text { dores; } e\end{array}$ \\
\hline 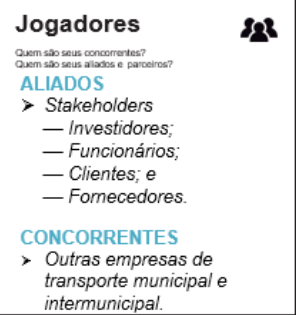 & 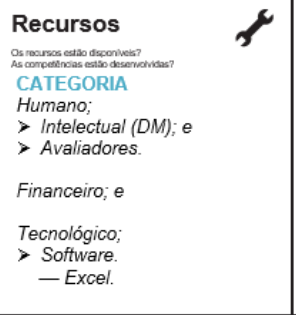 & & & 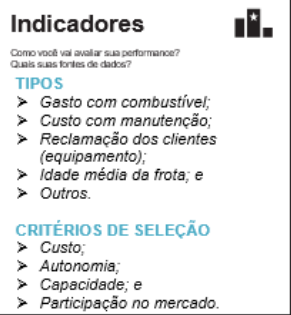 & 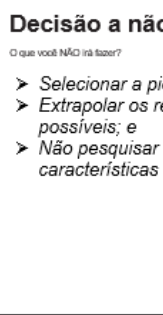 & $\begin{array}{l}\text { fazer } \boldsymbol{X} \\
\text { alternativa; } \\
\text { ursos } \\
\text { undo as } \\
\text { s produtos. }\end{array}$ \\
\hline \multicolumn{3}{|c|}{ 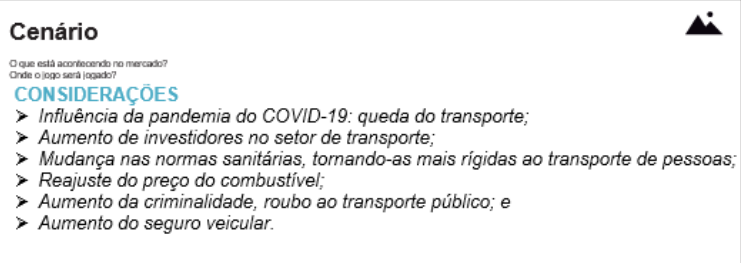 } & \multicolumn{4}{|c|}{ 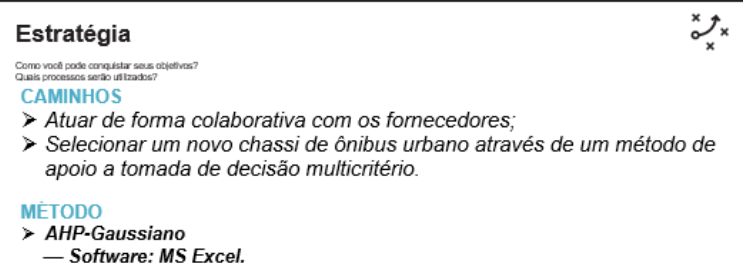 } \\
\hline
\end{tabular}

Fonte: Autores (2021)

O Quadro de Tomada de Decisões, Figura 1, é uma excelente ferramenta para realizar a estruturação do problema. A primeira etapa é realizar o preenchimento do espaço reservado 
para a Recompensa, onde constará informações sobre os ganhos que serão ou poderão ser adquiridos com o projeto, posterior, deverá ser realizado o preenchimento do Cenário e da Estratégia, respectivamente, onde no primeiro é preenchido o que está acontecendo nos ambientes interno e externo e no segundo o que será utilizado para conquistar os objetivos. A segunda etapa é o preenchimento das Regras, dos Desafios, dos Jogadores e dos Recursos, nesta ordem. A terceira e última etapa, é o preenchimento das Alternativas, dos Indicadores, da Decisão a fazer e da Decisão a não fazer, respectivamente.

Segundo Gomes (2020) o modelo visual, o Quadro de Tomada de Decisões, é uma ferramenta que auxilia na organização e na visão sistêmica de um projeto, de modo a tomar decisões estratégicas, entretanto auxilia também a tomada de decisão para direcionar o que seria decido em um momento mais à frente. O objetivo é reunir pessoas, fazer um estudo, levantamento e organização de informações, responder perguntas e definir critérios, com o intuito de se chegar a uma resposta para o projeto, ou problema.

\section{Metodologia}

\subsection{Questões de pesquisa}

As limitações deste trabalho estão compreendidas na busca por informações pertinentes ao processo de tomada de decisão. Foram utilizadas informações de apenas dois fabricantes, a Mercedes-Benz e a Volkswagen, pois existe uma limitação de informações técnicas que não constam nas fichas técnicas expostas online, que estejam abertas ao público em geral, de outros fabricantes, como, Volvo, Iveco, Agrale e Scania, por exemplo. Com isto, foi difícil conseguir informações de outros modelos, concorrentes aos impostos no processo decisório, para serem inseridos no problema.

\subsection{Seleção dos participantes e caso estudado}

Os participantes são os próprios autores deste trabalho e quanto ao direcionamento, fica por conta da seleção do melhor chassi de ônibus urbano, nas alternativas e atributos préselecionados, cujo intuito é extrair o melhor das alternativas e suas características.

\subsection{Procedimentos de coleta}


A coleta das informações foi realizada a partir de documentos abertos, como as fichas técnicas dos modelos Mercedes-Benz OF-1721 e o MAN (VWCO) 17.230 OD, e publicações via internet, jornais e revistas, como a Revista Quatro Rodas e o Estadão, e, também, informações fornecidas pela Federação Nacional Distribuição Veículos Automotores (Fenabrave).

\subsection{Procedimento de análise de dados}

Os dados e informações foram levantados, tratados e analisados, através de planilhas e Tabelas, utilizando o software MS Excel. A análise foi realizada de forma qualitativa e quantitativa. Os dados foram comparados entre diferentes fontes para se obter maior confiabilidade ao longo do processo decisório.

\subsection{Procedimento de validação}

Para uma maior robustez e confiabilidade dos resultados obtidos, além do MS Excel, foi utilizado o Gaussian AHP Software Web (v.1). Todos os cálculos do processo decisório foram realizados através do software MS Excel, onde foram inseridas as informações das características de cada chassi. Neste processo de decisão foi utilizado apenas um decisor, pois não há subjetividade nas informações, já que os dados técnicos são expostos pelos fabricantes. O próprio software gera os resultados validados pelo tomador de decisão.

\section{Resultados e Discussão}

\subsection{Estruturação do problema}

A estruturação do problema foi apresentada no item 3.2. Quadro de Tomada de Decisão, Figura 1, facilitando a visão geral do projeto. O objetivo para a resolução do problema apresentado é selecionar a melhor opção de chassi de ônibus urbano, utilizando como método de Apoio a Tomada de Decisão Multicritério o AHP-Gaussiano, com auxílio do software MS Excel, com validação através do Gaussian AHP Software Web (v.1).

Para este caso, a seleção de um novo chassi de ônibus urbano, foram consideradas as seguintes informações:

A primeira etapa:

—Em Recompensa, podemos definir as MOTIVAÇÕES: Cumprir as leis; Atrair novos clientes; Fidelizar clientes; e Aumentar a receita. 
—Em Cenário, foram definidas as influências do ambiente interno e externo, atual, onde as CONSIDERAÇÕES: Influência da pandemia do COVID-19: queda do transporte; Aumento de investidores no setor de transporte; Mudança nas normas sanitárias, tornando-as mais rígidas ao transporte de pessoas; Reajuste do preço do combustível; Aumento da criminalidade, roubo ao transporte público; e Aumento do seguro veicular.

—Em Estratégia, foram definidos os caminhos e o método a ser utilizado. Em CAMINHOS: Atuar de forma colaborativa com os fornecedores; Selecionar um novo chassi de ônibus urbano através de um método de apoio a tomada de decisão multicritério; e MÉTODO: AHP-Gaussiano com auxílio do software MS Excel e Gaussian AHP Software Web (v.1).

A segunda etapa:

—Em Regra, deve inserir todos os dados importantes que regulam o projeto, aquilo que dirige, rege, ou ainda, a norma, ou a fórmula que indica o modo apropriado de agir. Neste projeto, foram inseridas algumas regras pertinentes para os autores, de forma genérica.

—Em Desafio, está atrelada as informações que são ações ou efeitos, que provocam grandes obstáculos que devem ser ultrapassados, ou pelo menos entendidos como existentes, para formalização e aplicação do projeto. São as barreiras compreendidas pelos autores. EMPECILHO: Obter informações aprofundadas das características das alternativas (chassis); Compatibilidade com determinadas carrocerias que serão selecionadas futuramente; Produção (entrega) mais lenta devido à pandemia; Substituir a frota dos antigos veículos com os novos (venda dos antigos a longo prazo); e Treinamentos de operação e manutenção.

—Em Jogadores, será empregado todos os participantes, como os Aliados e os Concorrentes, desde as partes envolvidas no processo até outras empresas do mesmo setor que competem diretamente com suas atividades. ALIADOS: Stakeholders (Investidores; Funcionários; Clientes; e Fornecedores); e CONCORRENTES: Outras empresas de transporte municipal e intermunicipal.

—Em Recursos, é empregado tudo que a empresa dispõe para poder realizar seus objetivos impostos no projeto. São os meios pecuniários, bens materiais, capital humano, entre outros recursos concernentes ao objetivo instaurado. CATEGORIA: 
Humano, como intelectual (DM) e avaliadores; Financeiro; e Tecnológico, como Software empregado.

A terceira etapa:

—Em Alternativas, divide-se em alternativas utilizadas no processo decisório (Opções de Produtos) e alternativas de fundos de captação de recursos financeiros (Financeiro). As Opções de Produto, serão inseridas no método AHP-Gaussiano para se realizar o processo de tomada de decisão multicritério. Foram pré-selecionadas apenas duas das principais marcas do mercado, que juntas somam mais da metade da participação no mercado (Market Share) de chassis de ônibus no Brasil, segundo a Fenabrave (2020). OPÇÕES DE PRODUTOS: Mercedes-Benz; e Volkswagen; e FINANCEIRO: Empréstimos; e Programas de financiamento.

—Em Indicadores, foram definidos em duas vertentes, os Tipos de indicadores a serem observados, o que levou a observação da necessidade de compra de novos chassis, por exemplo, e o indicador para uso como Critério de Seleção, este será utilizado como atributo no processo decisório. TIPOS: Gasto com combustível; Custo com manutenção; Reclamação dos clientes (equipamento); Idade média da frota; e Outros. CRITÉRIOS DE SELEÇÃO: Custo; Autonomia; Capacidade; e Participação no mercado.

—Em Decisão a fazer e Decisão a não fazer, como propriamente diz, deverão ser definidas as ações no escopo para que fique claro a todos os envolvidos.

\subsection{Seleção do chassi urbano}

Existem duas definições para o chassi, o chassi, propriamente dito, e o chassi monobloco. De acordo com o dicionário, chassi é um "quadro de aço onde estão montados os órgãos necessários à locomoção de um veículo, de um vagão, sobre o qual é montada a respectiva carroçaria", objeto do problema. Já o chassi monobloco, "de uma única peça: chassi monobloco", sendo a base mais a carroceria do veículo.

Neste artigo, como já mencionado, foram selecionadas duas alternativas, o Mercedes-Benz OF-1721 e o MAN (VWCO) 17.230 OD, Figura 2 e 3, respectivamente. A falta de informações sobre outros modelos concorrentes fizeram com que houvesse a limitação das alternativas neste processo decisório. Porém, em um cenário real, as informações estarão mais 
próximas das empresas, já que os fabricantes protegem boa parte delas, disponibilizando apenas para potenciais clientes.

As alternativas e os critérios, pré-selecionados de acordo com a importância para os autores:

- Alternativas: (A1) Mercedes-Benz OF-1721 L; e (A2) MAN (VWCO) 17.230 OD; e

—Critérios: (C1) Potência (cv); (C2) Torque (mkgf); (C3) Tanque Combustível (L); (C4) Peso Chassi (Kg); (C5) Carga Útil (Kg); (C6) Velocidade (Km/h); (C7) Comprimento (cm); (C8) Largura (cm); (C9) Preço (R\$); e (C10) Market Share (\%).

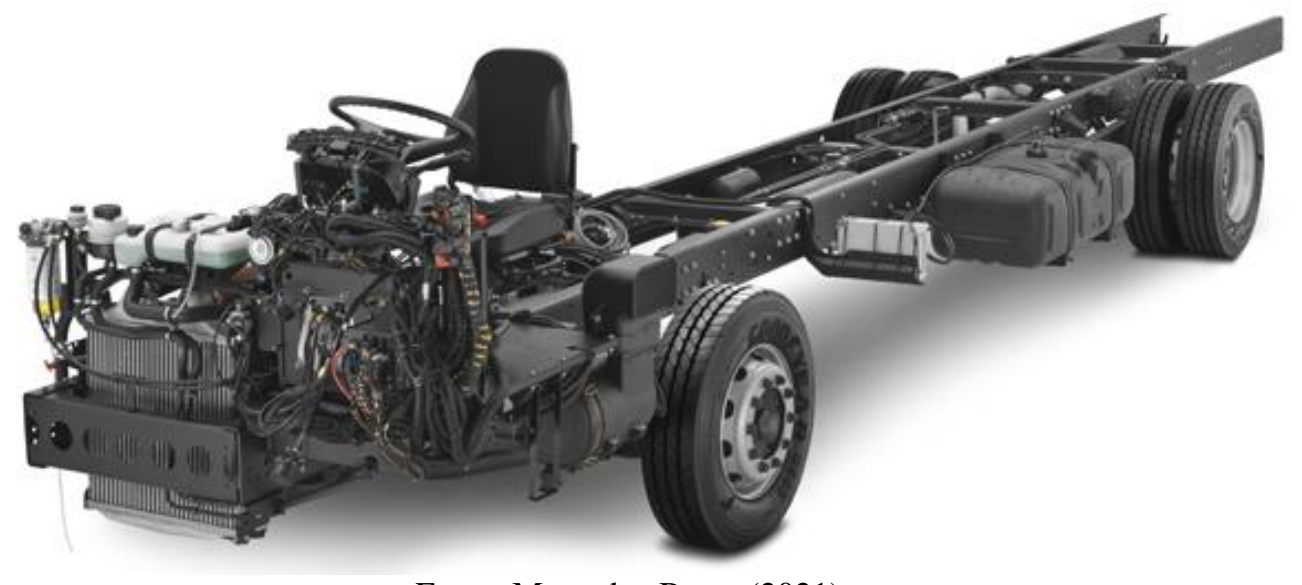

Fonte: Mercedes-Benz (2021)

O chassi MB OF-1721 é o líder de vendas em seu seguimento e a MAN/ Volkswagen é vicelíder em produção de chassis de ônibus, no Brasil. 


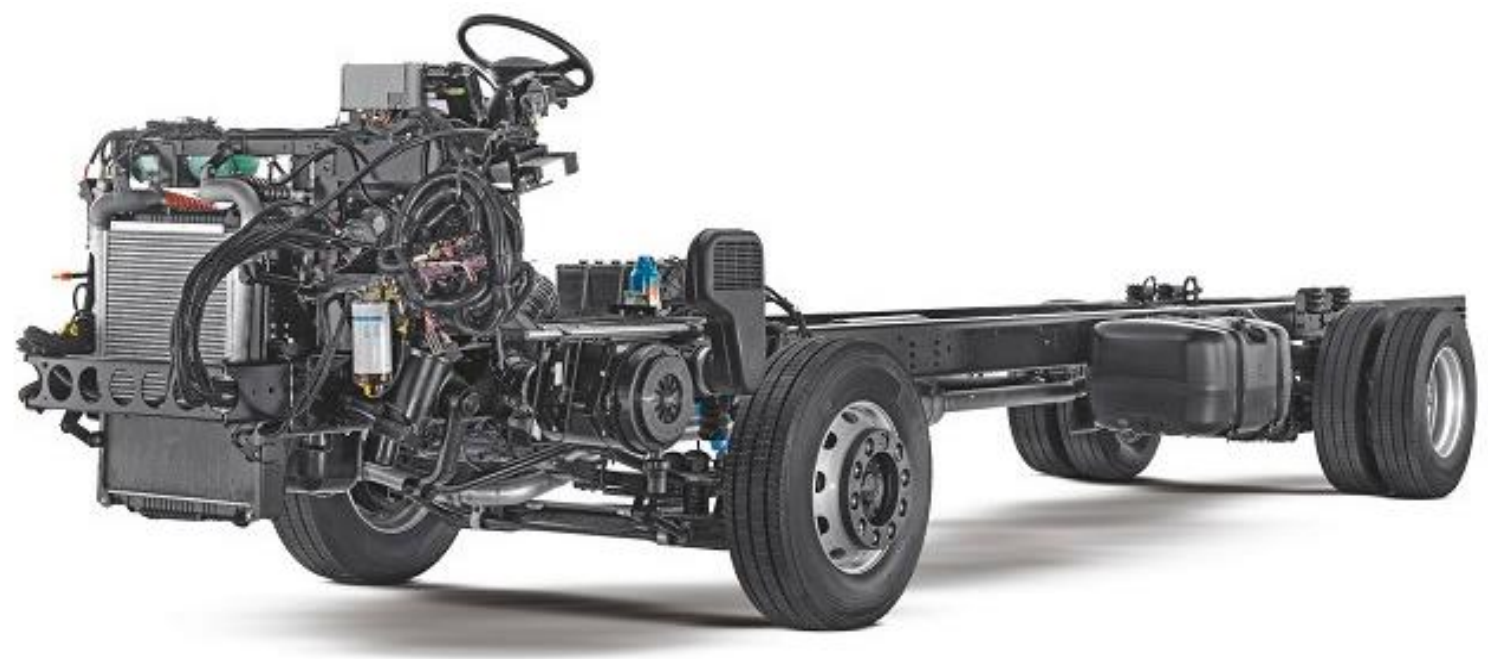

Fonte: MAN VWCO (2021)

\subsubsection{Aplicação do AHP}

Antes de realizar o método AHP-Gaussiano foi realizado o método original AHP, para efeito de comparação dos resultados. Na Tabela 1 é definido a matriz de decisão com as alternativas e os atributos.

Tabela 1 - Matriz de decisão - AHP

\begin{tabular}{|c|c|c|c|c|c|c|c|c|c|c|}
\hline & MAX & MAX & MAX & MIN & MAX & MAX & MAX & MAX & MIN & MAX \\
\hline & $\begin{array}{l}\underset{3}{0} \\
\cdot \frac{\pi}{0} \\
\frac{0}{0} \\
\stackrel{0}{0}\end{array}$ & 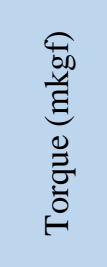 & 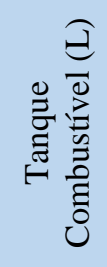 & 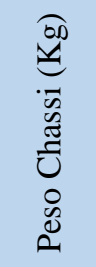 & 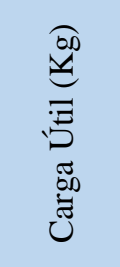 & 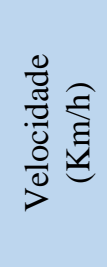 & 总 & 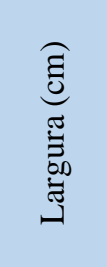 & 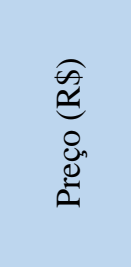 & 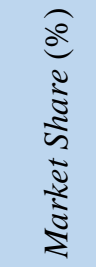 \\
\hline $\begin{array}{c}\text { Mercedes- } \\
\text { Benz - } \\
\text { OF-1721 }\end{array}$ & 208 & 79,5 & 300 & 4810 & 12.190 & 111 & 1176,9 & 244,2 & 342.171 & 56,76 \\
\hline $\begin{array}{c}\text { MAN } \\
\text { /VWCO } \\
17230\end{array}$ & 226 & 87 & 275 & 4820 & 12.480 & 112 & 1076,5 & 243,5 & 237.092 & 23,37 \\
\hline
\end{tabular}

Fonte: Autores (2021)

Posterior, são realizados todos os cálculos pertinentes ao método AHP, e por fim é gerado o resultado, Tabela 2, a seguir.

Tabela 2 - Ordenação - AHP 


\begin{tabular}{|c|c|c|c|}
\hline Mercedes-Benz - OF-1721 & 0,5246 & $52,46 \%$ & 1 \\
\hline MAN/ VWCO 17.230 & 0,4754 & $47,54 \%$ & 2 \\
\hline
\end{tabular}

Fonte: Autores (2021)

A alternativa preferível de acordo com o AHP é o Mercedes-Benz OF-1721, com aproximadamente 52,5\%, seguido pelo MAN/ VWCO 17.230, com aproximadamente 47,5\%.

\subsubsection{Aplicação do AHP-Gaussiano}

A primeira etapa é inserir as alternativas e os atributos na matriz de decisão, conforme Tabela 1. A próxima etapa é realizar a normalização da matriz de decisão, Tabela 3.

Tabela 3 - Matriz de decisão normalizada

\begin{tabular}{cccccccccccc}
\hline & MAX & MAX & MAX & MIN & MAX & MAX & MAX & MAX & MIN & MAX \\
\hline & C1 & C2 & C3 & C4 & C5 & C6 & C7 & C8 & C9 & C10 \\
\hline A1 & 0,4793 & 0,4775 & 0,5217 & 0,5005 & 0,4941 & 0,4978 & 0,5223 & 0,5007 & 0,4093 & 0,7083 \\
\hline A2 & 0,5207 & 0,5225 & 0,4783 & 0,4995 & 0,5059 & 0,5022 & 0,4777 & 0,4993 & 0,5907 & 0,2917 \\
\hline
\end{tabular}

Fonte: Autores (2021)

Após realizar a normalização, passa-se para a etapa de cálculo da média, desvio padrão e do Fator Gaussiano, e a normalização do Fator Gaussiano.

Tabela 4 - Média, desvio padrão e fator Gaussiano

\begin{tabular}{ccccccccccccc}
\hline & MAX & MAX & MAX & MIN & MAX & MAX & MAX & MAX & MIN & MAX \\
\hline & C1 & C2 & C3 & C4 & C5 & C6 & C7 & C8 & C9 & C10 \\
\hline Média & 0,5 & 0,5 & 0,5 & 0,5 & 0,5 & 0,5 & 0,5 & 0,5 & 0,5 & 0,5 \\
\hline Desvio Padrão & 0,0293 & 0,0319 & 0,0307 & 0,0007 & 0,0083 & 0,0032 & 0,0315 & 0,0010 & 0,1283 & 0,2946 \\
\hline $\begin{array}{c}\text { Fator Gaussiano } \\
\text { Fator Gaussiano }\end{array}$ & 0,0587 & 0,0637 & 0,0615 & 0,0015 & 0,0166 & 0,0063 & 0,0630 & 0,0020 & 0,2565 & 0,5893 \\
\hline \begin{tabular}{c} 
Normalizado \\
\hline
\end{tabular} & 0,0524 & 0,0569 & 0,0549 & 0,0013 & 0,0149 & 0,0057 & 0,0563 & 0,0018 & 0,2292 & 0,5266 \\
\hline
\end{tabular}


A próxima etapa é realizar a ponderação da matriz normalizada, onde será realizado a multiplicação do Fator Gaussiano coma matriz normalizada.

Tabela 5 - Matriz normalizada e ponderada

\begin{tabular}{cccccccccccc}
\hline & MAX & MAX & MAX & MIN & MAX & MAX & MAX & MAX & MIN & MAX \\
\hline & C1 & C2 & C3 & C4 & C5 & C6 & C7 & C8 & C9 & C10 \\
\hline A1 & 0,0251 & 0,0272 & 0,0287 & 0,0007 & 0,0073 & 0,0028 & 0,0294 & 0,0009 & 0,0938 & 0,3730 \\
\hline A2 & 0,0273 & 0,0297 & 0,0263 & 0,0007 & 0,0075 & 0,0028 & 0,0269 & 0,0009 & 0,1354 & 0,1536 \\
\hline
\end{tabular}

Fonte: Autores (2021)

A partir da matriz normalizada e ponderada é gerado a ordenação das alternativas, a partir da soma dos valores dos atributos de cada alternativa, do maior para o menor valor.

Tabela 6 - Ordenação - AHP-Gaussiano

\begin{tabular}{cccc}
\hline Alternativas & AHP - Valor & AHP - Valor (\%) & Ordem \\
\hline Mercedes-Benz - OF-1721 & 0,5889 & $58,89 \%$ & 1 \\
\hline MAN/ VWCO 17.230 & 0,4111 & $41,11 \%$ & 2 \\
\hline
\end{tabular}

Fonte: Autores (2021)

A alternativa preferível de acordo com o AHP-Gaussiano é o Mercedes-Benz OF-1721, com aproximadamente 59\%, seguido pelo MAN/ VWCO 17.230, com aproximadamente $41 \%$.

\section{Discussão dos resultados}

Em direção com o mercado, a melhor opção foi o Mercedes-Benz OF-1721. Vale ressaltar que este chassi, até o momento, é o produto mais vendido no Brasil, deste segmento. O chassi selecionado, através do método multicritério AHP e AHP-Gaussiano, é considerado a melhor opção para o decisor deste problema, em determinados critérios e suas relevâncias e, também, percepções pessoais sobre o mercado. Cada decisor poderá obter resultados diferentes do apresentado até aqui, inclusive se considerarmos mais alternativas e mais critérios no processo decisório.

O chassi de ônibus urbano selecionado, é condizente com a opção do mercado, já que a Mercedes-Benz assume 57\% do mercado no ano de 2020, um valor expressivo. Com isto, no proposto, o resultado foi satisfatório para os decisores. 


\section{Considerações finais}

O caso apresentado busca auxiliar as empresas de transporte de cargas ou pessoas na seleção de um novo veículo, indiferente do propósito, para diversos fins como modernização da frota ou até mesmo para outras situações que se deseja tomar uma ação decisória utilizando os métodos AHP e AHP-Gaussiano. Para uma maior assertividade é importante realizar uma análise aprofundada dos critérios a serem utilizados, assim como das alternativas a serem julgadas. Para trabalhos futuros, recomendam-se outras abordagens de estruturação do problema e outros métodos de Apoio a Tomada de Decisão, e, também, a continuação do trabalho com a seleção de uma carroceria, como Marcopolo, CAIO Induscar, Mascarello, entre outras.

\section{Referências}

ALVES, Pedro Marthos; et al. Aplicabilidade de um problema de mix ótimo de produção na área de vendas em uma associação estudantil. ENEGEP, Paraná, ed. 40, p. 1-10, 20 de out. de 2020

Anuário 2020: O desempenho da Distribuição Automotiva no Brasil. Federação Nacional da Distribuição de Veículos Automotores - FENABRAVE, 2020. Disponível em: <http://www.fenabrave.org.br/>. Acesso em: 08 de jun. de 2021.

FELTRIN, Aline. Venda de caminhões cresce 15,7\% em maio; veja o ranking de 2021. Estadão, 2021. Disponível em: <https://estradao.estadao.com.br/caminhoes/venda-de-caminhoes-cresce-157-em-maio-veja-oranking-de-2021/>. Acesso em: 08 de jun. de 2021.

FRANCO, Mateus Müller; et al. Aplicação de um método multicritério para a seleção de uma empresa terceirizada de aferição e manutenção de equipamentos hospitalares. ENEGEP, Paraná, ed. 40, p. 1-16, 20 de out. de 2020.

GOMES, Andrei Eduardo de Souza. Teoria dos jogos aplicada na educação profissional para desenvolvimento de competência em tomada de decisões estratégicas. 2020. [178 f.]. Dissertação (Programa de Mestrado Profissional em Gestão da Economia Criativa) - Escola Superior de Propaganda e Marketing, [Rio de Janeiro].

GOMES, Luiz Flavio Autran Monteiro; GOMES, Carlos Francisco Simões. Princípios e Métodos para Tomada de Decisão: enfoque multicritério. 6. ed. São Paulo: Atlas, 2019.

MOREIRA, Miguel Ângelo Lellis; SANTOS, Marcos dos; GOMES, Carlos Francisco Simões. Gaussian AHP Software Web (v.1). 2021.

OF 1721L/59: Dados Técnicos. Mercedes-Benz, 2021. Disponível em: <https://www.mercedesbenz.com.br/onibus/onibus-urbano/dados-tecnicos>. Acesso em: 08 de jun. de 2021.

RIBEIRO, Rodrigo. A insana (e proibida) sensação de domar um chassi de ônibus sem carroceria. Revista Quatro Rodas, 2020. Disponível em: <https://quatrorodas.abril.com.br/testes/a-insana-e-proibida-sensacao-dedomar-um-chassi-de-onibus-sem-carroceria/>. Acesso em: 08 de jun. de 2021.

SANTOS, Marcos dos; COSTA, Igor Pinheiro de Araujo; GOMES, Carlos Francisco Simões. Multicriteria decision-making in the selection of warships: a new approach to the AHP method. International Journal of the Analytic Hierarchy Process, 13(1). 2021. <https://doi.org/10.13033/ijahp.v13i1.833>. 
Sustentabilidade - Boletim de Tendências. Gestão de frotas: Práticas sustentáveis para pequenos negócios. Serviço Brasileiro de Apoio às Micro e Pequenas Empresas (SEBRAE), 2016. Disponível em: $<$ http://sustentabilidade.sebrae.com.br/sites/Sustentabilidade>. Acesso em: 08 de jun. de 2021.

TADAIESKY, Dhiordan Cunha; et al. Aplicação da pesquisa operacional na redução de custos com manutenção preventiva de um operador logístico: criação de um plano de compras otimizado. ENEGEP, Paraná, ed. 40, p. 1-16, 20 de out. de 2020.

Volksbus 17.230 OD/ODS: Especificações Técnicas. Volkswagen Caminhões e Ônibus/ MAN, 2021. Disponível em: <https://www.vwco.com.br/onibus/Urbano?id=5>. Acesso em: 08 de jun. de 2021. 